\title{
Clinicopathological correlation of retinal pigment epithelial tears in exudative age related macular degeneration: pretear, tear, and scarred tear
}

B A Lafaut, S Aisenbrey, C Vanden Broecke, R Krott, C P Jonescu-Cuypers, S Reynders, K U Bartz-Schmidt

\begin{abstract}
Aims-To analyse the histopathology of vascularised pigment epithelial detachments and tears of the retinal pigment epithelium (RPE) in age related macular degeneration (AMD).

Methods-The light microscopic architecture of 10 surgically removed subretinal specimens-three vascularised pigment epithelial detachments, four recent tears, and three scarred tears as a manifestation of AMD-were studied and correlated with the angiographic findings.

Results-Recent tears: a large fibrovascular membrane was found to be originally situated in Bruch's membrane. About half of the surface of the fibrovascular tissue was denuded of RPE and diffuse drusen. The RPE and diffuse drusen had retracted and rolled up, covering a neighbouring part of the intra-Bruch's fibrovascular membrane. The rolled up RPE and diffuse drusen were not interspersed with fibrovascular tissue but lay superficial to the intra-Bruch's fibrovascular membrane itself. Scarred tears: a collagen capsule surrounded the rolled up diffuse drusen and RPE. Fibrovascular tissue was found inside the rolled up material, predominantly at its choroidal side.

Conclusion-The area of choroidal neovascularisation associated with a vascularised pigment epithelial detachment and a tear of the RPE may be larger than was hitherto thought or indicated by fluorescein angiography. This neovascular tissue may be present within the bed of the RPE tear, as well as at the site of the scrolled up RPE.
\end{abstract}

University Eye Clinic, Joseph-StelzmannStrasse 9, D-50931 Cologne, Germany B A Lafaut

S Aisenbrey

R Krott

C P Jonescu-Cuypers

K U Bartz-Schmidt

Ghent University

Hospital,

Ophthalmology, De

Pintelaan 185, B-9000

Gent, Belgium

B A Lafaut

S Reynders

Ghent University Hospital, Pathology C Vanden Broecke

Correspondence to: B A Lafaut, Ghent University Hospital, Department of Ophthalmology, De Pintelaan 185, 9000 Ghent, Belgium

bart.lafaut@rug.ac.be

Accepted for publication 27 November 2000
(Br 7 Ophthalmol 2001;85:454-460)

A tear of the retinal pigment epithelium (RPE) is a common complication of a pigment epithelial detachment (PED) in the elderly, either occurring spontaneously or after laser photocoagulation. ${ }^{1-10}$ The patient usually experiences a sudden drop in visual acuity at the time of tearing; good vision is only rarely maintained after tearing of the macular RPE. ${ }^{11}{ }^{12}$ Hoskins et $a l^{1}$ described the clinical and fluorescein angiographic characteristics of tears of the RPE for the first time in 1981. Hoskins et $a l^{1}$ and Chuang and Bird ${ }^{10}$ did not recognise choroidal neovascularisation in the majority of their patients and suggested that it played only a minor part if at all, whereas
Coscas et $a l^{2}$ and Gass $^{6}{ }^{7}$ believed that choroidal neovascularisation was instrumental in the tearing of the RPE. Coscas et $a l^{13}$ identified angiographic indications for high risk of tearing by analysis of pretear angiograms. They recognised uneven filling of the PED with a remarkably hypofluorescent paracentral area as the most noteworthy feature. ${ }^{13}$

Very few clinicopathological correlations of tears are available. ${ }^{14}$ These demonstrate histopathologically the presence of associated choroidal neovascularisation. ${ }^{14}$ Green et $a l^{15}$ have recognised tears of the RPE in a series of postmortem eyes with disciform scars that may represent an end stage.

Recently, surgical specimens of vascularised PED and tears of the RPE have become available as new interest has arisen in the surgical removal of choroidal neovascularisation in age related macular degeneration. Foveal translocation or displacement of the foveal neuroretina towards an area with healthier RPE may offer a better functional outcome than removal of the neovascular membrane alone where the foveal neuroretina lies on a defect in the RPE.

We have analysed the histoarchitecture of surgically removed submacular tissue in three eyes with a vascularised PED and in seven eyes with a tear of the RPE. We suggest a flow chart of events that eventually lead to a scarred tear supported by the available clinicopathological studies. This may contribute to a better understanding of this vision threatening complication of age related macular degeneration.

\section{Materials and methods}

STUDY POPULATION

All surgical specimens from eyes with either a PED or a spontaneous tear of the RPE selected from a consecutive series of 200 age related macular degeneration specimens are included in this study with the exclusion of eight PED associated with a "deep retinal vascular anomalous complex" or a "chorioretinal anastomosis" which are the subject of a separate study. ${ }^{16}$ Three eyes with a vascularised PED (cases 1-3) as well as seven eyes with an established tear (cases 4-10) were included. All patients had experienced a recent drop in visual acuity (within 3 months) in the study eye except for three patients with a less recent tear of the RPE (cases 8-10).

\section{CLINICAL EXAMINATION}

All 10 patients had a standard ophthalmological examination including fundus photography and fluorescein angiography not more than 14 
Table 1 Summary of the clinical findings

\begin{tabular}{|c|c|c|c|c|c|}
\hline Case & Sex & Age & Tearing & Fundus and fluorescein angiographic findings & Indocyanine green angiographic findings \\
\hline 1 & $\mathrm{~F}$ & 61 & - & Vascularised PED, non-homogeneous filling & Underlying ill defined plaque \\
\hline 2 & M & 79 & - & "Pretear" PED, paracental hypofluorescent zone & Plaque occupying entire lesion/PED \\
\hline 3 & $\mathrm{M}$ & 63 & - & Vascularised PED, notch & Marginal hot spot \\
\hline 4 & $\mathrm{~F}$ & 78 & $\begin{array}{l}1 \text { month } \\
-1 \text { month }\end{array}$ & $\begin{array}{l}\text { No subretinal fibosis, some surrounding blood vascular } \\
\text { net at level of rolled up RPE, } \\
\text { Tearing vascularised PED, vascular net inside PED small } \\
\text { subretinal haemorrhages at one edge }\end{array}$ & $\begin{array}{l}\text { Speckled hyperfluorescence in rolled up RPE, surrounded by } \\
\text { plaque, denuded area isofluorescent }\end{array}$ \\
\hline 5 & $\mathrm{~F}$ & 75 & $\begin{array}{l}4-6 \text { weeks } \\
-5 \text { months }\end{array}$ & $\begin{array}{l}\text { No subretinal fibrous tissue, no vascular net } \\
\text { "Pretear" PED, paracentral hypofluorescent zone }\end{array}$ & - \\
\hline 6 & M & 80 & $\begin{array}{l}2 \text { months } \\
-3 \text { months }\end{array}$ & $\begin{array}{l}\text { Vascular net at level of rolled up RPE and in the area of } \\
\text { denuded RPE } \\
\text { Vascularised PED, notch }\end{array}$ & $\begin{array}{l}\text { Speckled hyperfluorescence in rolled up RPE disappearing } \\
\text { within a hyperfluorent plaque, denuded area included } \\
\text { Marginal plaque }\end{array}$ \\
\hline 7 & $\mathrm{~F}$ & 75 & $21 / 2$ months & $\begin{array}{l}\text { Rolled up RPE embedded in massive subretinal } \\
\text { haemorrhage, no vascular net }\end{array}$ & - \\
\hline 8 & M & 65 & 4 months & $\begin{array}{l}\text { Some subretinal fibrosis, some surrounding blood no } \\
\text { vascular net }\end{array}$ & Speckled hyperfluorescence in rolled up RPE \\
\hline 9 & M & 76 & 4 months & $\begin{array}{l}\text { No subretinal fibrous tissue, no vascular net } \\
\text { Rolled up RPE, some subretinal blood }\end{array}$ & $\begin{array}{l}\text { Speckled hyperfluorescence in rolled up RPE, surrounded by } \\
\text { plaque, denuded area hyperfluorescent } \\
\text { Speckled hyperfluorescence in rolled up RPE, surrounded by } \\
\text { plaque, denuded area hyperfluorescent }\end{array}$ \\
\hline 10 & $\mathrm{~F}$ & 75 & $5-6$ months & $\begin{array}{l}\text { Rolled up RPE surrounded by subretinal fibrous tissue } \\
\text { and massive subretinal haemorrhage }\end{array}$ & - \\
\hline
\end{tabular}

Previous angiographic documentation, indicated in italics, is available for four patients. The indication of time corresponds to the time interval between first and second angiographic examination.

days before surgery. Seven also had indocyanine green angiography not more than 14 days before surgery. Indocyanine green angiography was not performed in two patients because of a massive subretinal haemorrhage. In one it was contraindicated because of allergic antecedents. Angiographic documents from earlier examinations were available in four patients with a torn RPE. The fluorescein angiogram was obtained after intravenous injection of 5 $\mathrm{ml}$ sodium fluorescein 10\% (Alcon Pharma $\mathrm{GmbH}$, Freiburg, Germany) with a Canon fundus camera (Canon Inc, Neuss, Germany) linked to a Kodak high resolution camera (OIS, Ophthalmic Imaging Systems, Polytech Ophthalmologie GmbH, Rossdorf, Germany). Pictures were taken up to 10 minutes after intravenous injection. The indocyanine green angiogram was obtained after intravenous injection of $50 \mathrm{mg}$ indocyanine green (Pulsion Medical Systems, Munich, Germany) dissolved in $10 \mathrm{ml}$ with the same camera system. Pictures were taken up to 30 minutes after intravenous injection. None of these patients had diseases, such as high myopia, multifocal choroiditis, and angioid streaks, predisposing to choroidal neovascularisation other than age related macular degeneration. The clinical findings are summarised in Table 1.

SURGICAL PROCEDURE

The macula was translocated in nine patients (full macular translocation with $360^{\circ}$ retinotomy). In one patient the specimen was extracted without rotation at the time of removal of a massive subretinal haemorrhage.

HISTOLOGICAL ANALYSIS

The specimens were fixed in $10 \%$ neutrally buffered formalin, dehydrated, and embedded in paraffin for light microscopy. The membranes were serially sectioned and stained in a stepped fashion with Masson trichrome (MTC) and periodic acid Schiff (PAS). Multiple sections of each membrane were stained with phosphotungstic acid haematoxylin histochemical stain for fibrin (PTAH).

\section{Results}

The fluorescein and indocyanine green angiographic findings of these patients are summarised in Table 1.

\section{PRETEAR STAGE-PED}

Two of three PED had pretear characteristics (cases 1 and 2)-namely, a non-homogeneous filling with a paracentral hypofluorescent zone. Indocyanine green angiography revealed a plaque undermining the PED in these two cases. Fibrovascular tissue was found in the two corresponding specimens. In one specimen the fibrovascular membrane was located with certainty in the Bruch's membrane or under the RPE as it was entirely covered by RPE and diffuse drusen; however, in the central two thirds of the specimen the RPE and diffuse drusen had detached from the fibrovascular membrane itself (Fig 1). The fibrovascular membrane of the other specimen could not be oriented as no adherent RPE and diffuse drusen were found on serially sectioned material, but RPE and diffuse drusen were located distant from the fibrovascular membrane itself. The third PED (case 3) had a notch on fluorescein angiography that corresponded to a marginal hot spot on indocyanine green angiography. Fibrovascular tissue was found that was at least in part located in the Bruch's membrane. Another part of the membrane could not be oriented as it was not covered by RPE and diffuse drusen. Some RPE and diffuse drusen were located distant from the fibrovascular tissue.

\section{FRESH TEAR STAGE}

Three relatively recent tears of the RPE with characteristic angiographic features (cases 4, 5, and 7) had a rather similar histoarchitecture. A large fibrovascular membrane was found to be originally situated in the Bruch's membrane since at its edges native RPE and diffuse drusen were recognised and allowed orientation (Figs 2 and 3). About half of the surface of the fibrovascular tissue was denuded of RPE and diffuse drusen except for its outer margin. 




Figure 1 Specimen corresponding to a vascularised pigment epithelial detachment with non-homogeneous fluorescein filling. Indocyanine green angiography revealed an ill defined underlying plaque (case 1). The RPE and diffuse drusen have partially detached from the intra-Bruch's fibrovascular tissue. Masson trichrome, bar $=100 \mu \mathrm{m}$.

The RPE and diffuse drusen appeared to have drusen were not interspersed with fibrovascuretracted and rolled up, covering a neighbouring part of the intra-Bruch's fibrovascular lar tissue but lay superficial to the intra-Bruch's membrane. The rolled up RPE and diffuse

fibrovascular membrane itself. The rolled up $\mathrm{RPE}$ and diffuse drusen were partially covered
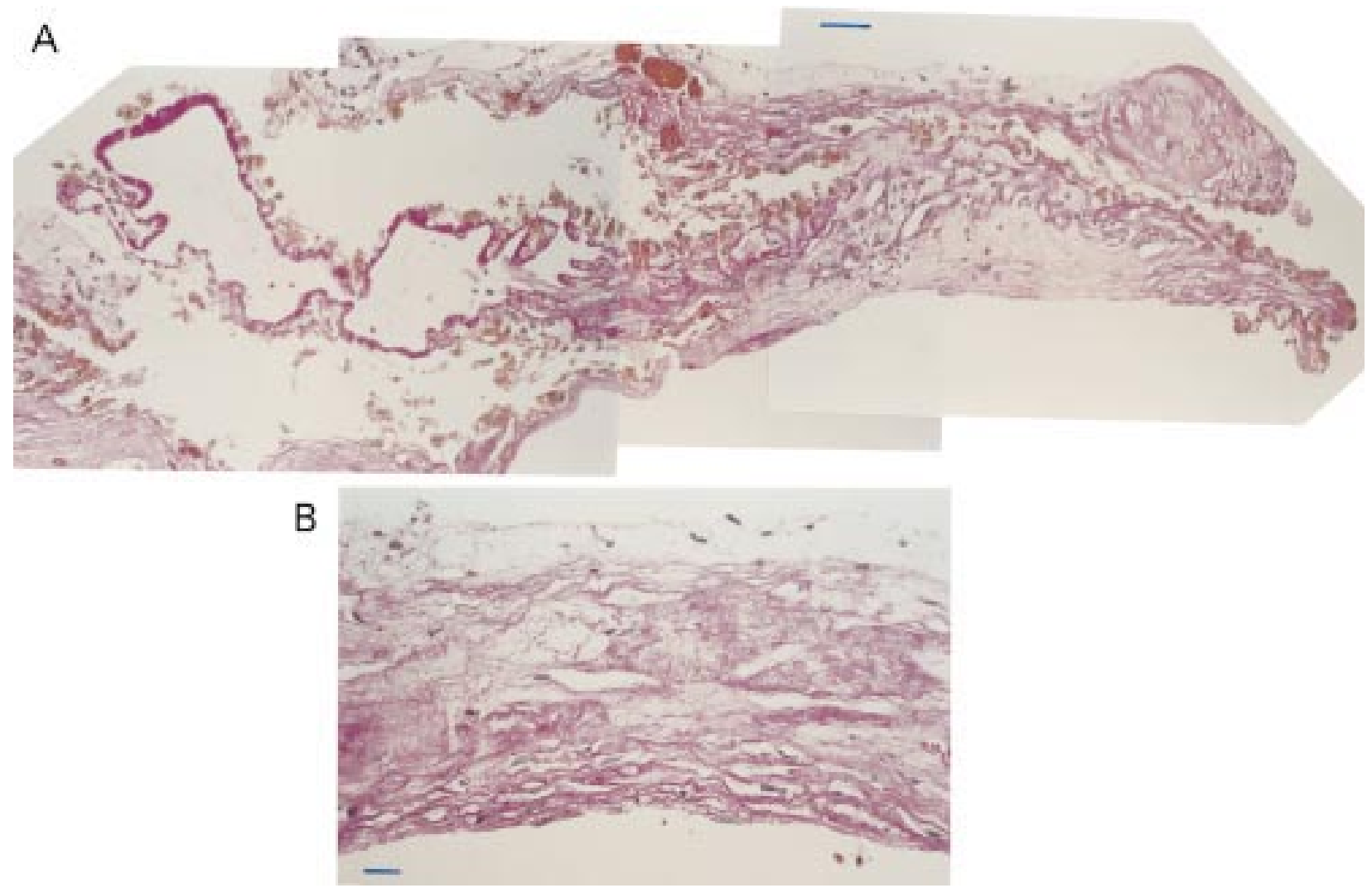

Figure 2 Specimen corresponding to a recent tear (case 5). (A) At one edge of the specimen intra-Bruch's fibrovascular tissue is recognised, more centrally to it rolled up RPE and diffuse drusen are seen that are only partially covered by fibrovascular tissue and amorphous debris on their retinal side. (B) Towards the opposite edge, rather fibrous fibrovascular membrane is observed denuded of RPE and diffuse drusen but covered by a thin layer of amorphous debris. Periodic acid Schiff, bar $=50 \mu \mathrm{m}$ in $(A)$ and $25 \mu \mathrm{m}$ in (B). 

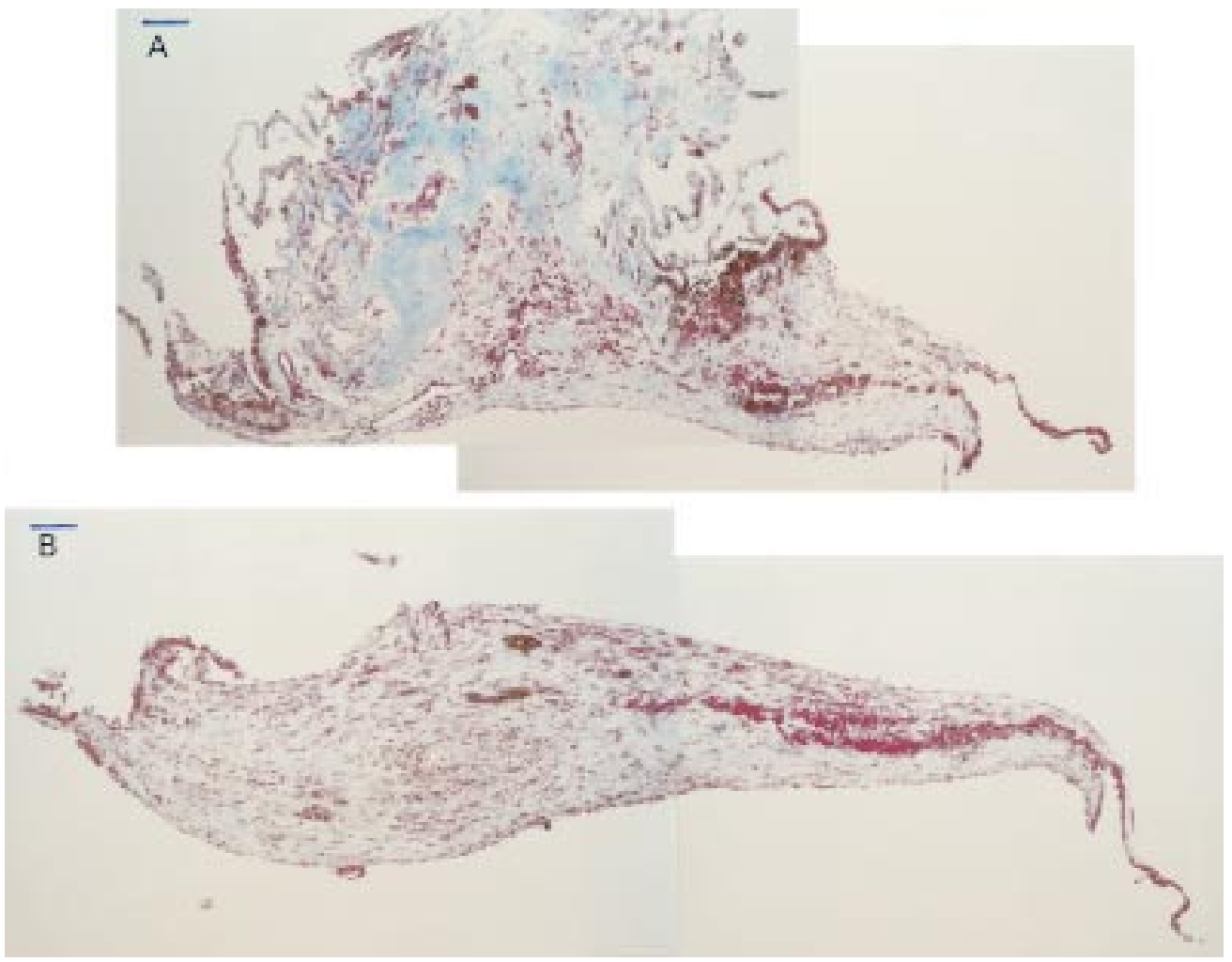

Figure 3 Specimen corresponding to a recent tear (case 7). (A) At the level of the rolled up RPE and diffuse drusen, at both edges RPE and diffuse drusen allow orientation of the section. (B) Distant to the rolled up RPE and diffuse drusen, fibrovascular tissue is found that is centrally denuded from RPE and diffuse drusen. The latter structures are, however, identified at the edge of the section and suggest that at least the majority at this level is situated in the Bruch's membrane. Masson trichrome, bar $=100 \mu \mathrm{m}$ in $(A)$ and $(B)$.

by proteinaceous debris and the remains of outer segments in two specimens partially covered by a thin fibrovascular membrane in one specimen and entirely covered by a thin fibrovascular membrane in another specimen. The covering fibrovascular tissue was only poorly vascularised. A moderately dense infiltration of inflammatory cells (predominantly lymphocytes) was seen in the neighbourhood of the rolled up RPE and diffuse drusen.
The angiographic appearance of case 6 was somewhat unusual: fluorescein angiography identified a vascular net with profuse leakage, indocyanine green angiography indicated the rolled up RPE with speckled hyperfluorescence embedded in a plaque. The corresponding specimen consisted of fibrovascular tissue located subretinally as well as under the RPE. The subretinal component was smaller in diameter than the intra-Bruch's component.

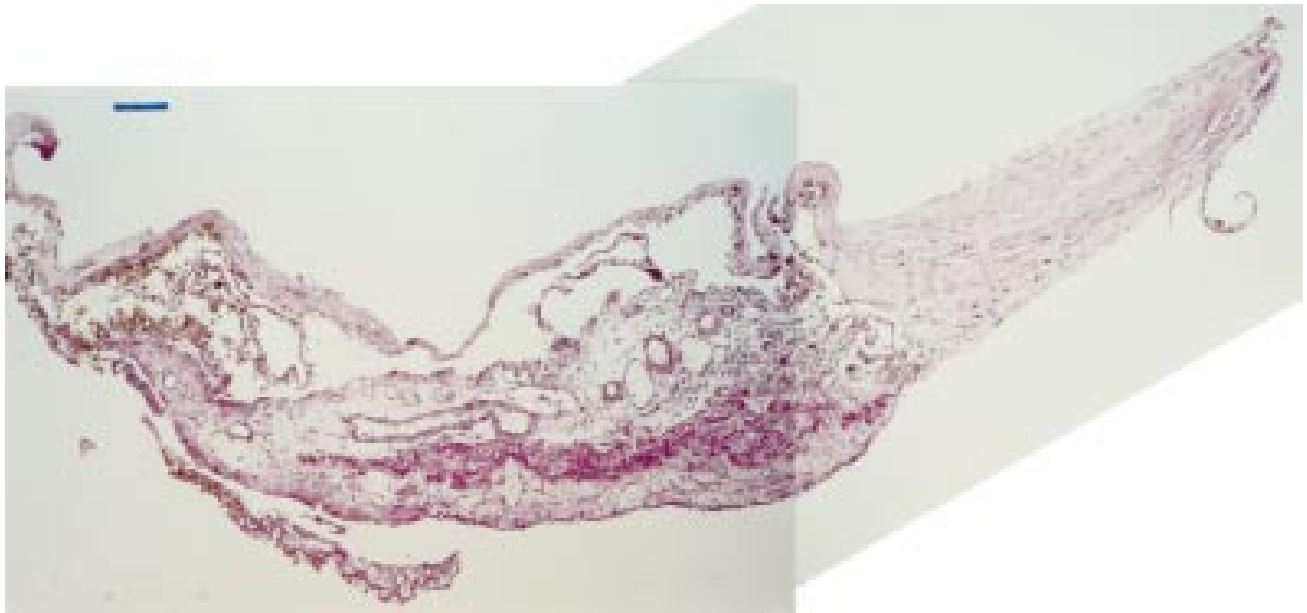

Figure 4 Specimen corresponding to a less recent tear (case 8). Rolled up RPE and diffuse drusen, which are covered by a thin fibrocellular membrane on their retinal side, are readily recognised. On their choroidal side fibrovascular tissue is observed with large bore vessels and a moderately strong inflammatory cell infiltration. Adjacent to this part of the specimen, fibrovascular tissue denuded of RPE and diffuse drusen but covered by a thin layer of amorphous debris is found. At one edge of the specimen, RPE, diffuse drusen, and a thin layer of intra-Bruch's fibrovascular tissue are found that has, however, turned over as shown on serial sectioning. At the opposite edge, RPE, diffuse drusen and a thin layer of intra-Bruch's fibrovascular tissue is found that has also turned over but does not physically make contact with the edge of the section itself at this level. Periodic acid Schiff, bar $=100 \mu \mathrm{m}$. 


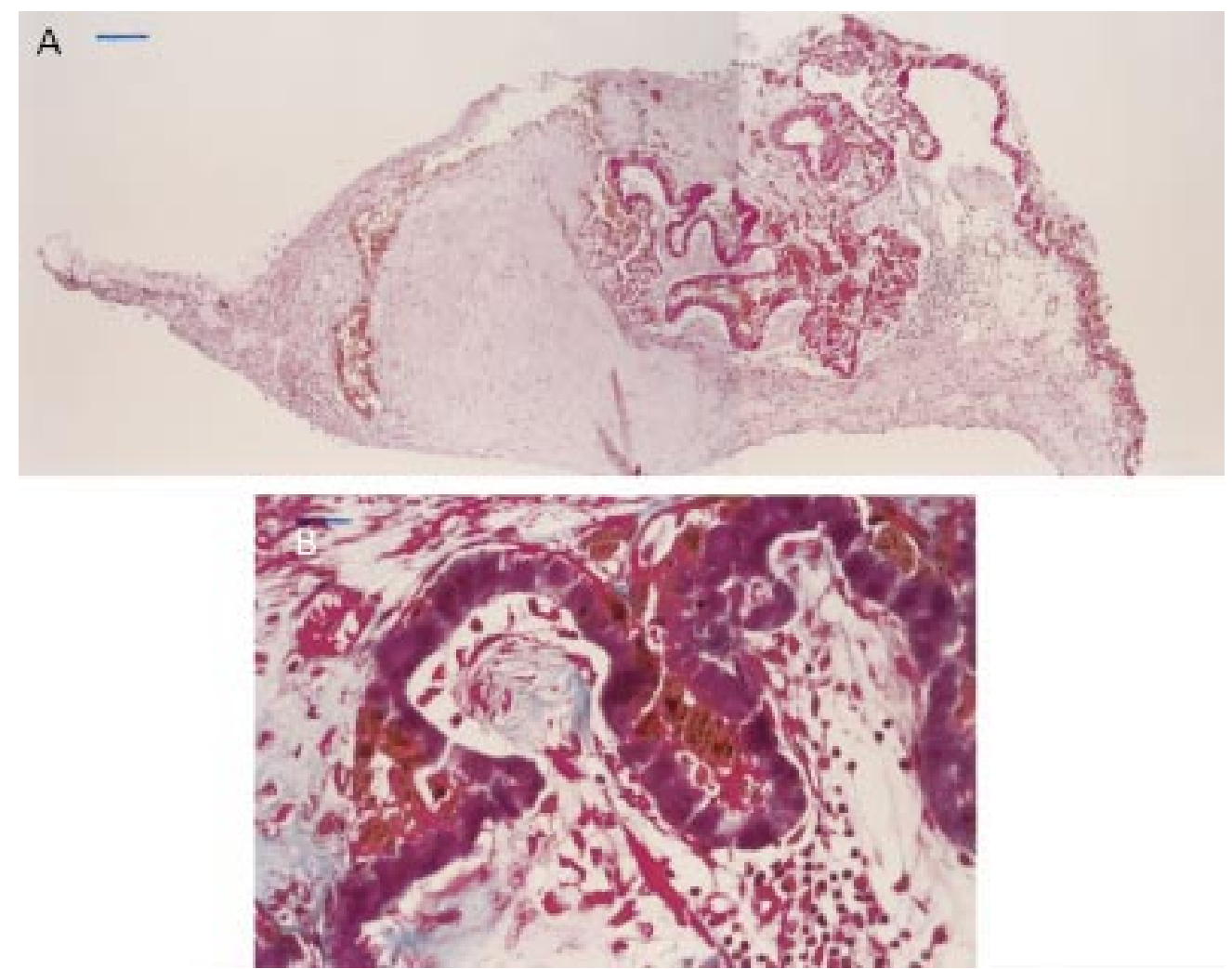

Figure 5 Specimen corresponding to a scarred tear (case 10). (A) Rolled up RPE and diffuse drusen are found centrally embedded in a fibrous capsule. At one side an intra-Bruch's fibrovascular membrane is recognised whereas the fibrovascular tissue at the other side of the specimen cannot be attributed since it is entirely denuded of RPE and diffuse drusen. In some areas the diffuse drusen are not accompanied by pigmented cells and a group of pigmented cells has migrated from the diffuse drusen and appears to separate the densely collagenised nodule from the remainder of the specimen. A moderately strong inflammatory cell infiltration is seen at the choroidal side of the rolled up diffuse drusen. (B) Detail of rolled up drusen with interspersing fibrovascular and inflammatory tissue at their choroidal side. Masson trichrome, bar $=100 \mu \mathrm{m}$ in (A) and $25 \mu \mathrm{m}$ in (B).

Rolled up RPE and diffuse drusen were identified in between the two components and a part of the sub-RPE component was denuded of $\mathrm{RPE}$ and BLD.

SCARRED TEAR STAGE (CASES 8-10)

Basically an identical architecture was recognised as well in the three scarred tears of the RPE. The presence of a collagen capsule surrounding the rolled up diffuse drusen or the rolled up diffuse drusen and RPE were the most marked characteristic: the capsule was thin in case 8 (Fig 4) but thick and dense in the other two (Fig 5). Fibrovascular tissue was found inside the rolled up material in cases 9 and 10 , predominantly at its choroidal side. A moderate inflammatory cell infiltration was seen near the diffuse drusen in cases 8 and 10 . Melanin bearing cells had migrated distant from the diffuse drusen, either towards the retinal surface of the capsule or towards the adjacent fibrovascular membrane denuded of RPE and diffuse drusen in cases 9 and 10 . Such pigmented cells appeared to separate the densely collagenised capsule from the remainder of the specimen.

\section{Discussion}

It has recently been recognised that differing histoarchitectural characteristics may explain fluorescein angiographic features of age related choroidal neovascularisation. ${ }^{17}$ This study was

undertaken to find out whether the architecture of a pretear PED and of a tear of the RPE could be reconstructed from a series of surgically removed specimens. We have used light microscopy as the major cellular components (RPE, vascular endothelium, fibrocytes, macrophages, and photoreceptors) as well as extracellular components (collagen, diffuse drusen, and fibrin) can be correctly identified by light microscopy alone. ${ }^{18}$ The diffuse drusen are seen as an extra layer between the RPE and the outer Bruch's membrane (defined here as Bruch's membrane), which is a granular, PAS positive deposition that stains metachromatically blue-purple on MTC. Diffuse drusen is a light microscopic term that corresponds to basal laminar and basal linear deposits, which are the electron microscopic characteristics of age related macular degeneration. ${ }^{19} 20$

Because there are almost no clinicopathological correlations of neovascularised PED, the histoarchitecture of this lesion is only poorly known. ${ }^{7021}$ Fluorescein angiography already gives an indication of the presence of neovascularisation when a notched or a reniform PED is demonstrated. ${ }^{22}$ Fluorescein angiography allows the identification of a "chorioretinal anastomosis" or a "deep retinal vascular anomalous complex" which is a peculiar lesion associated with a PED. ${ }^{23} 24$ The latter lesion is not further elaborated here. Specific types of vascularised PED have been described 

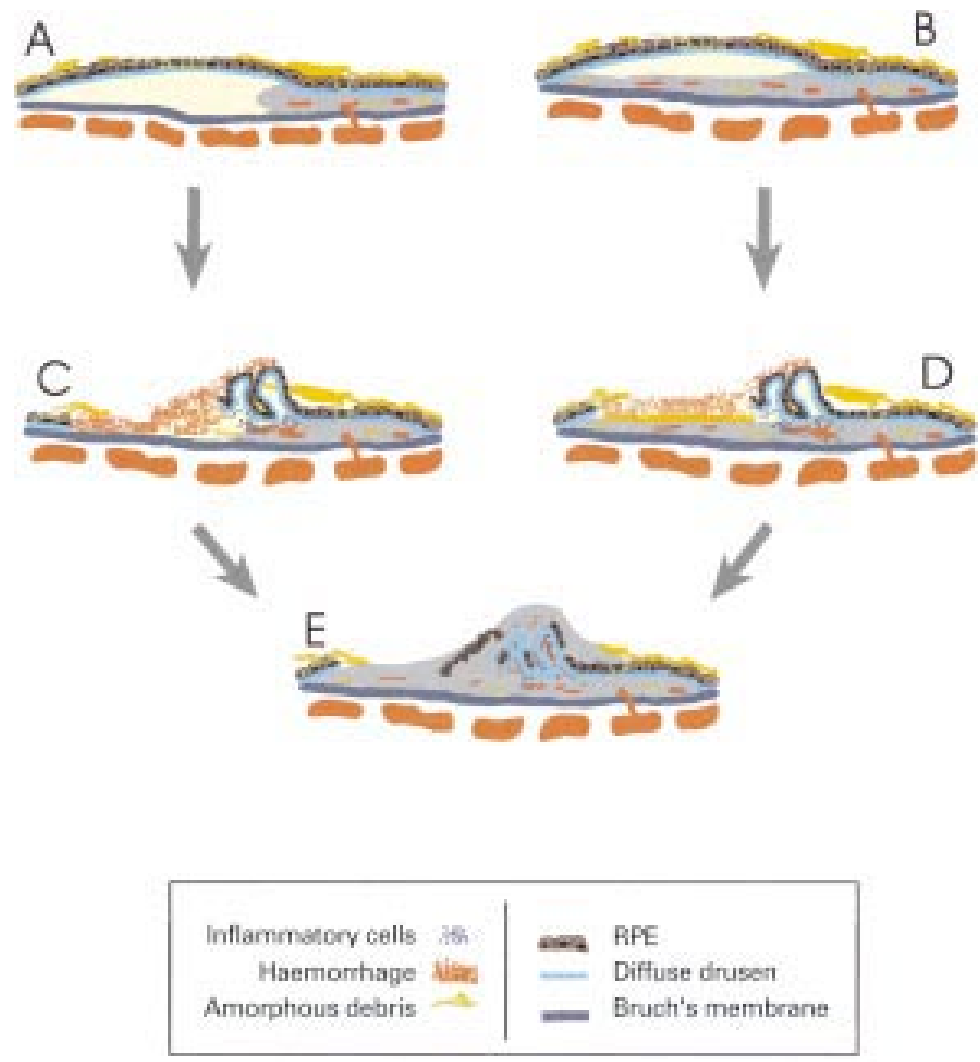

Figure 6 Hypothesis of a flow chart for the histoarchitectural stages that ultimately may lead to a scarred tear of the retinal pigment epithelium. (A) Corresponds to a vascularised $P E D$ with a plaque or hot spot, $(B)$ corresponds to a pretear PED, (C) and (D) correspond to fresh tears respectively without or with denuded intra-Bruch's fibrovascular tissue, and finally $(E)$ represents a scarred tear.

with indocyanine green angiography. Either a marginal hot spot (a late hyperfluorescence smaller than one disc area) or a marginal plaque (a late hyperfluorescence equal or larger than one disc area) are the typical lesions observed. ${ }^{2526}$ The majority of these late hyperfluorescent lesions lie outside the PED itself. The hot spot or the plaque often correspond to a notch that was already identified by fluorescein angiography. It is hypothesised that these lesions correspond to intra-Bruch's fibrovascular choroidal neovascularisation at the edge of a PED (Fig 6A). ${ }^{25}{ }^{26}$ Less frequently, indocyanine green angiography may, however, reveal a plaque that has largely or even entirely undermined the associated PED as in cases 1 and 2 . This angiographic pattern suggests the presence of an intra-Bruch's fibrovascular membrane at the site of the PED (Fig 6B). The intra-Bruch's fibrovascular tissue was demonstrated in at least one pretear specimen. An extensive area of separation of the RPE together with the diffuse drusen from underlying intra-Bruch's fibrovascular tissue was observed. The detachment appears not to be an artefact because some proteinaceous fluid filled the lumen of the separation. In the second pretear specimen the RPE and diffuse drusen had entirely separated from the fibrovascular tissue. This would not have been likely if a pre-existing weakened adhesion was not present because it was not observed in a consecutive series of 31 classic or occult neovascular membranes without an associated
PED in age related macular degeneration. ${ }^{17}$ It appears that in these two cases detachment of the RPE and diffuse drusen from the underlying fibrovascular tissue corresponds to the clinical PED. Another argument that RPE and diffuse drusen may detach from underlying fibrovascular tissue if present is that a tear corresponds to rolled up RPE and diffuse drusen without associated fibrovascular tissue in relatively fresh specimens (Fig 6D). Fibrovascular tissue grown into the rolled up RPE and diffuse drusen is, however, observed in more chronic, scarred lesions (Fig 6E). Furthermore, the overlying proteinaceous fluid may intuitively explain the poor angiographic indication of the associated choroidal neovascularisation. IntraBruch's fibrovascular tissue was also found in the vascularised PED with a marginal hot spot. Unfortunately, the surgical specimens are fragile and may have been distorted when passing through the sclerotomy. More correlations will be needed to better understand the architecture of a vascularised PED.

Coscas et $a l^{2}$ and Gass ${ }^{6}{ }^{7}$ indicated the role of associated occult choroidal neovascularisation in the process of tearing. Their concept has been reinforced since the advent of indocyanine green angiography. The rolled up RPE is hypofluorescent on fluorescein angiography due to blockage by its pigmentation. A characteristic speckled hyperfluorescence of a variable degree is observed on indocyanine green angiography that indicates the presence of underlying choroidal neovascularisation. ${ }^{27-29}$ The indocyanine green angiographic characteristics of tears are, however, more complex. The speckled hyperfluorescence of the rolled up RPE may be associated with a plaque that may partly or entirely occupy the area denuded of RPE. This angiographic finding suggests that choroidal neovascularisation may even be present in areas denuded of RPE. It is well known that tearing triggers the formation of a disciform scar and that a disciform scar may explain the presence of a plaque..$^{30}$ However, such associated plaques are also found shortly after tearing of the retinal pigment epithelium before the tranformation into a scar has occurred. For example, we found a relatively large area of fibrovascular tissue, denuded of RPE and diffuse drusen neighbouring the rolled up tear in three of four relatively fresh tears (Fig 6D). This fibrovascular tissue may be responsible for the plaque surrounding the tear as was shown by indocyanine green angiography in the two examined cases. The observation suggests that choroidal neovascularisation is instrumental in the pathogenesis of pigment epithelial tears, but also indicates that the area of fibrovascular tissue may be more extensive than was hitherto thought. It is likely that the neovascular tissue had partly or entirely undermined the PED before tearing took place. This extent may not be readily recognised angiographically because of interference with the proteinaceous exudate of the overlying PED itself.

In conclusion, we suggest that the RPE with its diffuse drusen may progressively detach 
from the underlying intra-Bruch's fibrovascular membrane as a variant pathogenetic mechanism of a vascularised PED. It may not only explain a plaque largely undermining a PED but also a plaque surrounding torn RPE. Within a matter of months, the torn and rolled up RPE becomes embedded in a thick collageneous capsule, and melanin bearing cells, either RPE or melanophages, migrate. Both these changes may explain why the characteristic appearance of a tear of the RPE disappears with time.

1 Hoskins A, Bird AC, Sehmi K. Tears of detached retinal pigment epithelium. Br f Ophthalmol 1981;65:417-22.

2 Coscas G, Quentel G, Pinon F, et al. Déchirure spontanée de l'épithélium pigmentaire dans la région maculaire. Bull Soc Ophtalmol Fr 1982;82:815-20.

3 Cantrill HL, Ramsay RC, Knobloch WH. Rips in the pigment epithelium. Arch Ophthalmol 1983;101:1074-9. pigment epithelium. Arch Ophthalmol 1983;101:1074-9.
Decker WL, Sanborn GE, Ridley M, et al. Retinal pigment epithelial tears. Ophthalmology 1983;90:509-12.

epithelial tears. Ophthalmology 1983;90:509-12.
Green SL, Yarian D. Acute tear of the retinal pigment Green SL, Yarian D. Acute tear
epithelium. Retina 1983;3:16-20.

6 Gass JDM. Retinal pigment epithelial rip during krypton red laser photocoagulation. Am f Ophthalmol 1984;98:7006.

7 Gass JDM. Pathogenesis of tears of the retinal pigment epithelium. Br f Ophthalmol 1984;68:513-19.

8 Krishan NR, Chandra SR, Stevens TS. Diagnosis and pathogenesis of retinal pigment epithelial tears. $\mathrm{Am} \mathrm{f} \mathrm{Oph}$ thalmol 1985;100:698-707.

9 Nolthenius PAT, Deutman AF. Rips of the retinal pigment epithelium. Int Ophthalmol 1985;8:19-23.

10 Chuang EL, Bird AC. The pathogenesis of tears of the retinal pigment epithelium. Am $\mathcal{F}$ Ophthalmol 1988;105:28590.

11 Yeo JH, Marcus S, Murphy RP. Retinal pigment epithelial tears. Patterns and prognosis. Ophthalmology 1988;95:8tears.

12 Bressler NM, Finkelstein D, Sunnes JS, et al. Retinal pigment epithelial tears through the fovea with preservation of good visual acuity. Arch Ophthalmol 1990;108:1694-7.

13 Coscas G, Koenig F, Soubrane G. The pretear characteristics of pigment epithelial detachments. A study of 40 eyes. Arch Ophthalmol 1990;108:1687-93.
14 Toth CA, Pasquale AC, Graichen DF. Clinicopathologic correlation of spontaneous retinal pigment epithelial tears with choroidal neovascular membranes in age-related macular degeneration. Ophthalmology 1995;102:272-7.

15 Green WR, McDonnell PJ, Yeo JH. Pathologic features of senile macular degeneration. Ophthalmology 1985;92:61527

16 Lafaut BA, Aisenbrey S, Vanden Broecke C, et al. Clinicopathological correlation of deep retinal vascular anomalous complexes in age-related macular degeneration. Br f Ophthalmol 2000;84:1269-74.

17 Lafaut BA, Bartz-Schmidt KU, Vanden Broecke C, et al. Clinicopathological correlation in exudative age-related macular degeneration: histological differentiation between macular degeneration: histological differentiation between Ophthalmol, 2000;84:239-43.

18 Grossniklaus HE, Hutchinson AK, Capone A, et al. Clinicopathologic features of surgically excised choroidal neovascular membranes. Ophthalmology 1994;101:1099-111.

19 Sarks SH. New vessel formation beneath the retinal pigment epithelium in senile eyes. Br F Ophthalmol 1973;57:951-65.

20 Green WR, Enger C. Age-related macular degeneration histopathologic studies. The 1992 Lorenz E. Zimmerman lecture. Ophthalmology 1993;100:1519-35.

21 Green WR. Senile macular degeneration. In: Spencer WH, ed. Ophthalmic pathology: an atlas and textbook. 2nd ed. Philadelphia: WB Saunders, 1985:927-89.

22 Gass JDM. Stereoscopic atlas of macular diseases. 4 th ed. St Louis: Mosby, 1997:86-7.

23 Hartnett ME, Weiter JJ, Garsd A, et al. Classification of retinal pigment epithelial detachments associated with drusen. Graefes Arch Clin Exp Ophthalmol 1995;230:11-19.

24 Kuhn D, Meunier I, Soubrane G, et al. Imaging of chorioretinal anastomoses in vascularized retinal pigment epithelial detachments. Arch Ophthalmol 1995;113:1392-8.

25 Yannuzzi LA, Hope-Ross M, Slakter JS, et al. Analysis of vascularized pigment epithelial detachments using indocyanine green videoangiography. Retina 1994;14:99-113.

26 Guyer DR, Yannuzzi LA, Slakter JS, et al. Ophthalmology 1994;101:1727-37.

27 Arroyo JG, Schatz H, McDonald R, et al. Indocyanine green videoangiography after acute retinal pigment epithelial tears in age-related macular degeneration. Am $\mathcal{f}$ Ophthalmol 1997;123:377-85.

28 Coluciello M, Ginsburg LH, Sammartino JP. Indocyanine green angiographic evaluation of retinal pigment epithelial green angiographic evaluation

29 Giovannini A, Scassellati-Sforzolini B, Lafaut B, et al. Indocyanine green angiography of retinal pigment epithelial tears. Acta Ophthalmol Scand 1999;77:83-7.

30 Chuang EL, Bird AC. Repair after tears of the retinal pigment epithelium. Eye 1988;2:106-13. 